\title{
STUDY OF PROCESS OF ELECTRONIC FLOW REGULATION FOR SPRINKLING MACHINES
}

\author{
Mihnea Glodeanu ${ }^{1}$, Cristian Vasile ${ }^{1}$, Ion Saracin ${ }^{1}$, Adina Glodeanu ${ }^{2}$ \\ ${ }^{1}$ University of Craiova, Romania; ${ }^{2}$ University of Medicine and Pharmacy, Romania \\ mihneaglodeanu@yahoo.com, cristi_vasile_4you@yahoo.com, ion_saracin@yahoo.com, \\ glodeanuadina@yahoo.com
}

\begin{abstract}
The widespread use of electronic regulators in the construction of sprinkling machines has required the study of the adjustment performance achieved by these equipments, in specific working conditions, such as: modification the displacement velocity of the unit, or changing the working width during spraying. Study of the electronic adjustment process of the liquid flow with displacement velocity was performed under laboratory conditions, by simulating on a stand the real operating process. When a deviation occurs, the regulator acts on a motorized valve, which will correct the liquid flow to the value necessary to ensure the prescribed norm. The motorized valve has been mounted on the return circuit in the tank. An electromagnetic flow meter was installed downstream of this adjustment system to measure the values of the regulated flow. This type of flow meter has the advantages of being accurate, of not disturbing the flow and of having a standardized output signal of 4-20 mA, compatible with the requirements of the regulator and a programmable measuring range. The speed regime simulation was performed using a signal generator coupled to the input of the electronic controller. The analysis of the electronic flow regulation process was performed by using a data acquisition and processing program, which also allowed the calculation of treatment application errors. The analysis of the obtained results highlights in case of change of the displacement velocity a prompt response of the adjusting system, being necessary approx. $7.0 \mathrm{~s}$ for flow correction. The predominance of errors between $10 \%$ and $15 \%$ is not excessive and the cumulative value of the surfaces, on which the prescribed liquid norm has not been ensured, is insignificant. In the case of change of the working width, the errors of application of the treatment were higher, reaching up to approx. 20\%, but the adjusting system reacted faster because of lower overall hydraulic resistance.
\end{abstract}

Keywords: displacement velocity, electronic regulators, liquid flow.

\section{Introduction}

Testing in laboratory had as purpose establishing the performances of the electronic adjustment system, from the point of the quality of the adjusting process, as well as the consequences of inertia that characterizes the control system [1]. Experiments were performed simulating the real working process of a sprayer, equipped with an electronic regulator for specific working conditions [2;3]. Therefore, for a given situation, the regulator calculates the flow reference value with the following relation:

$$
Q=\frac{D \cdot L \cdot v}{600}, 1 \cdot \mathrm{ha}^{-1}
$$

where $\quad D-$ dose, $1 \cdot \mathrm{ha}^{-1}$;

$L$ - working width;

$v$-displacement velocity, $\mathrm{km} \cdot \mathrm{h}^{-1}$.

For the experimental research a method was used, which involves the application of signals at the input of the speed transducer in order to achieve the speed regime simulation [4-6]. The frequency of these signals goes through a range of values, for which (with adequate transducers) the output signal is measured. The control function of the electronic block is performed by the reaction circuit. In practice this circuit consists of: the control valve of liquid flow; the flow sensor, through which the compliance value of the prescribed liquid rate is controlled $[2 ; 3 ; 7]$.

In order to determine the relationship between the displacement velocity $(v)$ and the frequency of impulses generated by the speed transducer $\left(f_{v}\right)$ (simulated using the signal generator) it is necessary to have in view the following: the transducer for the measurement and conversion of the displacement velocity is mounted on a sprinkling machine with the radius of the wheel transport $R=0.4 \mathrm{~m}$; the number of teeth of the inductive wheel is $Z=36$. The following relation is obtained [8;9]:

$$
v=\frac{3.6 \cdot f_{v} \cdot 2 \pi \cdot R}{Z}, \mathrm{~km} \cdot \mathrm{h}^{-1}
$$


Also knowing the characteristics of the flow transducer $\left(K_{d}=10^{3} \mathrm{~cm}^{3}\right.$ per impulse), the relationship between the flow rate of the liquid (which passes through the transducer) and the appropriate frequency $\left(f_{Q}\right)$, generated from the flow transducer according to the relation can be established [10]:

$$
\begin{gathered}
Q=K_{d} \cdot f_{Q}, \\
Q=600 \cdot f_{Q} \cdot 10^{-3} 1 \cdot \mathrm{min}^{-1} .
\end{gathered}
$$

Analysis of evolution of the adjusted liquid flow was performed using a software for data acquisition and processing. The same software also allowed the calculation of error treatment application.

\section{Materials and methods}

The experimental research was carried out in laboratory conditions, mainly due to the technical difficulties encountered, when the measurements take place in real conditions, but also in terms of interpreting the results we could obtain.

The stand designed for study of the process of electronic flow regulation for sprinkling machines consists of two subunits (Fig. 1):

- a hydraulic circuit, which simulates the working process of a sprinkling machine;

- an electronic part for the acquisition of measurements and the simulation of a speed signal sent to the electronic controller.

The hydraulic circuit has the following main components.

1. Liquid tank, having a capacity of 12001.

2. Pumping system.

3. Flow regulator with a motorized valve, mounted on the pump discharge circuit; this regulator has the role of taking over the flow oscillations and thus ensuring stability of the liquid flow discharged by the pump; a LFC Liquid Flow Controller (type 8719) was used that supports the following standardized input signals: $0-5 \mathrm{~V} ; 0-10 \mathrm{~V} ; 0-20 \mathrm{~mA}$ or 4-20 mA, in order to adapt to the different measuring devices.

4. Electronic adjustment system; when a deviation occurs, the controller (type HC 6500) acts on a motorized valve, which will correct the liquid flow to the value necessary to ensure the prescribed norm.

5. Motorized valve for adjusting the liquid flow has been mounted on the return circuit in the tank, because its small section hole can cause a large pressure drop and a decrease in the flow available for the rest of the installation [11-13].

6. Electromagnetic flow meter (Sprayer Barn, model RFM60P), capable to measure a wide range of liquids at various flow rates: $3.8-2271 \cdot \mathrm{min}^{-1}$, mounted downstream of the adjustment system in order to measure the values of the regulated flow and to provide them to the data acquisition and processing system; this type of flow meter has the advantages of being accurate, of not disturbing the flow and of having a standardized output signal of 4-20 mA, compatible with the requirements of the regulator and a programmable measuring range; this device provides the workflow information to the electronic controller [11;14].

7. Spraying boom; having in view that the experiments were carried out in laboratory conditions, a spray boom with 5 sections was used; each section is equipped with 6 nozzles, mounted at $50 \mathrm{~cm}$ from each other, the total working width being $15 \mathrm{~m}$.

8. Distributor, equipped with five valves.

The measurement system and speed signal simulation have the following main components.

1. PC type HP $250 \mathrm{G} 7$.

2. Serial interface to ensure communication between the computer and peripheral devices.

3. Signal generator; as the simulation of the speed regime by using an inductive electromagnetic transducer is difficult (the speed being able to be changed only manually), a signal generator type Versatester E 0502 was used in the experiments; the output signal level was set to $200 \mathrm{mV}$ (signal that was applied to the input of the speed transducer, in order to achieve the speed regime simulation) [7]. 


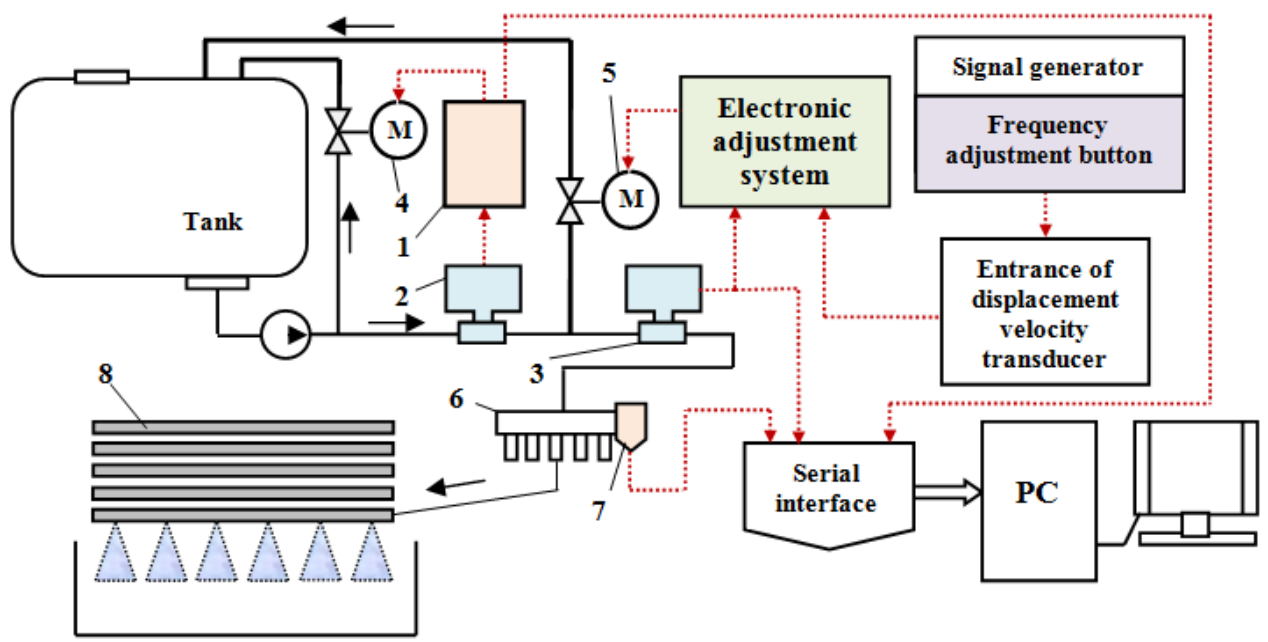

Fig. 1. Stand designed for study the process of electronic flow regulation: 1 - flow regulator;

2, 3 - electromagnetic flow meters; 4, 5 - motorized valves; 6 - distributor; 7 - pressure sensor; 8 - spraying boom

For simulating a progressive and constant variation of the displacement velocity (in $5 \mathrm{~s}$ ) it was considered that the field of frequency variation is in the range of $16-60 \mathrm{~Hz}$, corresponding to the speed of the sprayer, in the range of $4-15 \mathrm{~km} \cdot \mathrm{h}^{-1}[1 ; 9 ; 15]$.

Given that the sampling rate of the sensors is $25 \mathrm{~Hz}$, we change the speed for each $25 \mathrm{~s}$. It means that the gradual and continuous variations actually are a succession of small echelons, whose amplitude is equal to:

$$
\frac{1 \mathrm{~km} \cdot \mathrm{h}^{-1}}{5 \cdot 25}=0.008
$$

We can quantify the error made on the longitudinal distribution of the solution given the more realistic aspect of the speed evolution.

Suppose that the probability density function of these errors follows a normal law and considering that $99.5 \%$ of the errors are between $-3 \%$ and $+3 \%$ (tolerance range for the adjusting system), the standard deviation of the distribution is:

$$
\hat{\sigma}=\frac{3 \%}{2.58}=1.16, \%
$$

where 2.58 - estimated standard deviation.

The error of application of the treatment $(e)$ is calculated with the relation:

$$
e=\frac{Q_{R}-Q_{P}}{Q_{P}} \cdot 100=q_{r}, \%
$$

where $Q_{R}-$ real liquid flow, in $1 \cdot \mathrm{min}^{-1}$;

$Q_{P}$ - prescribed liquid flow, in $1 \cdot \mathrm{min}^{-1}$. if:

This will be different from 0 (exact compliance with the prescribed flow) in a very significant way,

$$
\frac{\left|q_{r}-0\right|}{\frac{\hat{\sigma}}{\sqrt{n}}} \geq t_{1-\alpha / 2},
$$

where $n$-number of observations used to determine the average error.

If $n=5$ and $\alpha=0.01$ (results $t_{1-\alpha / 2}=4.60$ ), we can obtain the value of the error calculated on 5 values, which will be considered different from 0 in a very significant way, if: 


$$
q_{r} \geq 4.60 \cdot \frac{\hat{\sigma}}{\sqrt{n}}=4.60 \cdot \frac{1.16}{\sqrt{5}}=2.39 \approx 2.5 \% .
$$

As soon as the average error calculated on 5 values is greater than $2.5 \%$, we will consider that it is not negligible and therefore the prescribed flow is not respected.

Investigations concerning the influence of the speed variation on the liquid flow adjusted, as well as on the longitudinal distribution of the spray solution, were carried out under the following conditions:

- progressive and constant variation of the working speed (situation very close to reality), from $5 \mathrm{~km} \cdot \mathrm{h}^{-1}\left(1.38 \mathrm{~m} \cdot \mathrm{s}^{-1}\right)$ to $6 \mathrm{~km} \cdot \mathrm{h}^{-1}\left(1.66 \mathrm{~m} \cdot \mathrm{s}^{-1}\right)$ in $5 \mathrm{~s}\left(\right.$ accelerated regime, $\left.a=+0.056 \mathrm{~m} \cdot \mathrm{s}^{-2}\right)$;

- progressive and constant variation of the working speed, from $6 \mathrm{~km} \cdot \mathrm{h}^{-1}$ to $5 \mathrm{~km} \cdot \mathrm{h}^{-1}$ in $5 \mathrm{~s}$ (decelerated regime, $a=-0.056 \mathrm{~m} \cdot \mathrm{s}^{-2}$ );

- $\quad$ prescribed dose of liquid $D=250 \mathrm{l} \cdot \mathrm{ha}^{-1}$;

- working width of the spraying boom, $L=15 \mathrm{~m}$ (5 sections of the spraying boom in operation).

Considering the calculation relationship of the prescribed liquid flow, in order to ensure the stability of the applied liquid dose, the adjustment system must correct the value of this parameter:

- from $31.21 \cdot \mathrm{min}^{-1}$ to $37.51 \cdot \mathrm{min}^{-1}$, in the case of an accelerated regime;

- from $37.51 \cdot \mathrm{min}^{-1}$ to $31.21 \cdot \mathrm{min}^{-1}$, in the case of a decelerated regime.

Investigations concerning the influence of the working width variation during the spraying process on the liquid flow adjusted, as well as on the longitudinal distribution of the spray solution, were carried out under the following conditions:

- $\quad$ working speed: constant, $v=6 \mathrm{~km} \cdot \mathrm{h}^{-1}$;

- prescribed dose of liquid $D=250 \mathrm{l} \cdot \mathrm{ha}^{-1}$;

- working width of the spraying boom, $L=12 \mathrm{~m}$ (4 sections of the spraying boom in operation);

- opening of the $5^{\text {th }}$ section of the spraying boom, in approx. $2 \mathrm{~s}$;

Under these conditions the adjustment system must correct the value of the prescribed flow from $301 \cdot \mathrm{min}^{-1}$ to $37.51 \cdot \mathrm{min}^{-1}$.

\section{Results and discussion}

Based on the flow values measured using the electromagnetic flow meter, the evolution of the regulated flow (compared to the reference value), in the case of an accelerated regime, is represented in the graph of Fig. 2.

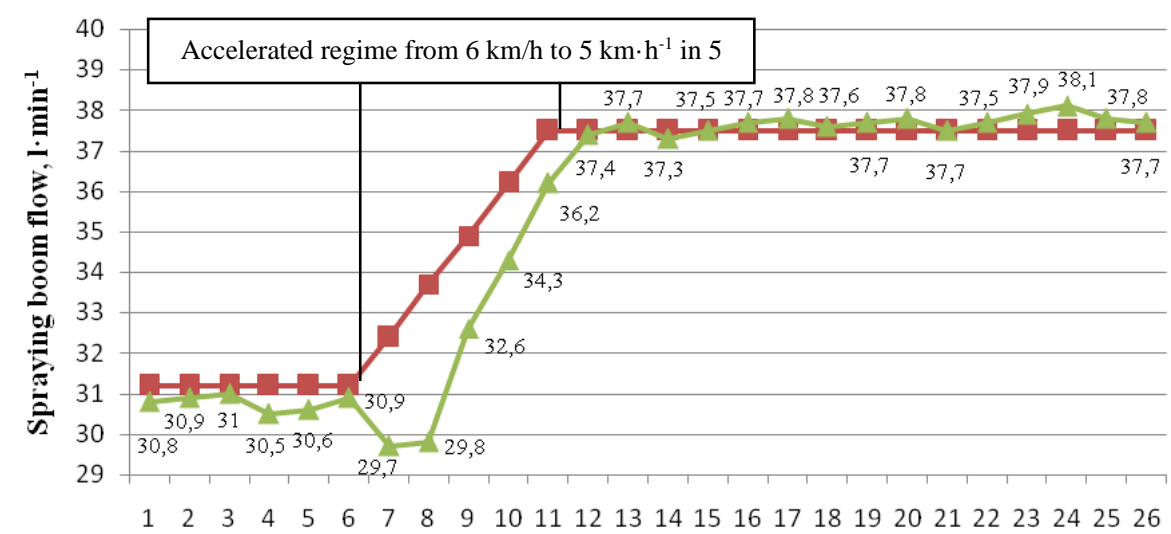

Time, $s$

$$
\rightarrow \text { Prescribed liquid flow } \quad-\text { Adjusted liquid flow }
$$

Fig. 2. Evolution of the regulated flow, compared to the reference value, in case of progressive and constant variation of the working speed from $5 \mathrm{~km} \cdot h^{-1}$ to $6 \mathrm{~km} \cdot \mathrm{h}^{-1}$ in $5 \mathrm{~s}$

Given the accuracy of the regulator, it starts operating only about 1.5 seconds after acceleration starts, so that the flow correction will start only about 2.8 seconds after the disturbance starts. 
Table 1 indicates the distances and areas corresponding to each category of treatment application errors during the liquid flow adjustment process.

Influence of the change of displacement velocity from $5 \mathrm{~km} \cdot \mathrm{h}^{-1}$ to $6 \mathrm{~km} \cdot \mathrm{h}^{-1}$ in $5 \mathrm{~s}$ on the Table 1 longitudinal distribution of the spray solution

\begin{tabular}{|c|c|c|c|c|c|}
\hline $\begin{array}{c}\text { Error class, } \\
\mathbf{\%}\end{array}$ & $\begin{array}{c}\text { Average } \\
\text { error, \% }\end{array}$ & Distance, $\mathbf{m}$ & $\begin{array}{c}\text { Cumulative } \\
\text { distance, } \mathbf{m}\end{array}$ & Surface, $\mathbf{~ m}^{\mathbf{2}}$ & $\begin{array}{c}\text { Cumulative } \\
\text { surface, } \mathbf{m}^{\mathbf{2}}\end{array}$ \\
\hline$-12.5 \ldots-15$ & 14.40 & 2.81 & 2.81 & 42.15 & 42.15 \\
\hline$-10 \ldots-12.5$ & 10.08 & 2.62 & 5.43 & 39.30 & 81.45 \\
\hline$-2.5 \ldots 5$ & 4.66 & 3.02 & 8.45 & 45.30 & 126.75 \\
\hline
\end{tabular}

Analysis of the obtained results shows that the area on which significant errors of application of the spray solution occurred (meaning more than $2.5 \%$ ) is relatively small $\left(126.75 \mathrm{~m}^{2}\right.$ ). It can be observed that the maximum errors of application of the treatment do not exceed $15 \%$, and the cumulative area on which large errors occurred (between $10 \ldots 15 \%$ ) is $81.45 \mathrm{~m}^{2}$.

The evolution of the regulated flow (compared to the reference value), in the case of a decelerated regime is represented in the graph (Fig. 3).

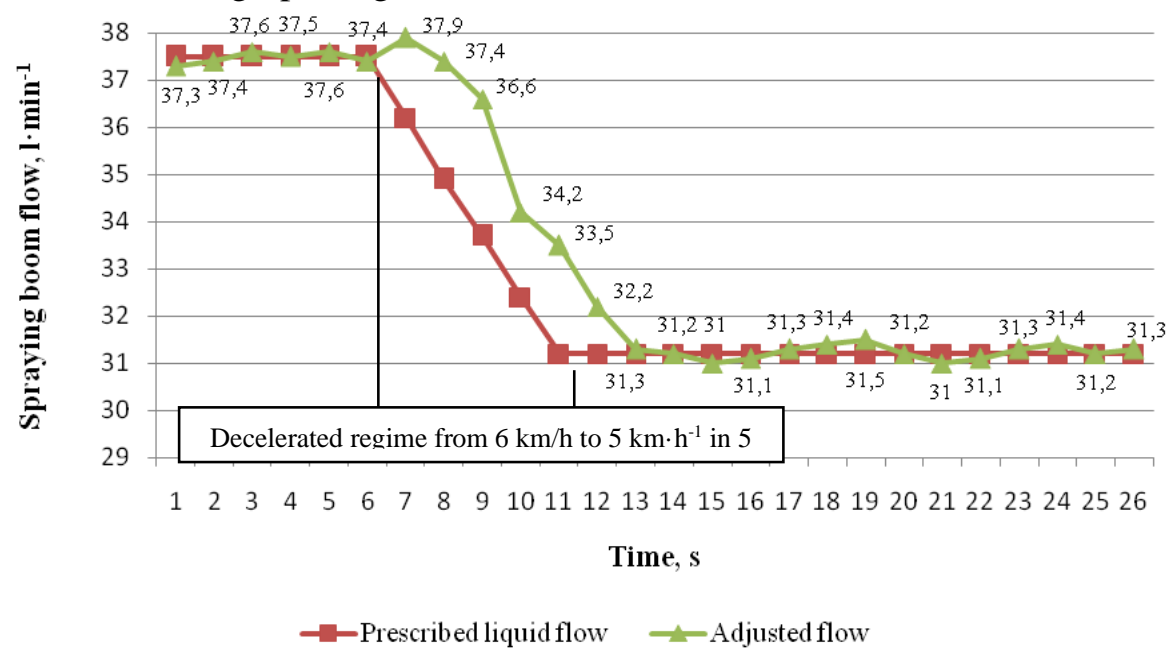

Fig. 3. Evolution of the regulated flow, compared to the reference value, in case of progressive and constant variation of the working speed from $6 \mathrm{~km} \cdot \mathrm{h}^{-1}$ to $5 \mathrm{~km} \cdot \mathrm{h}^{-1}$ in $5 \mathrm{~s}$

Table 2 indicates the distances and areas corresponding to each category of treatment application errors, during the liquid flow adjustment process (in case of a progressive and constant variation of the working speed from $6 \mathrm{~km} \cdot \mathrm{h}^{-1}$ to $5 \mathrm{~km} \cdot \mathrm{h}^{-1}$ in $5 \mathrm{~s}$ ).

Table 2

Influence of the change of displacement velocity from $6 \mathrm{~km} \cdot \mathrm{h}^{-1}$ to $5 \mathrm{~km} \cdot \mathrm{h}^{-1}$ in $5 \mathrm{~s}$ on the longitudinal distribution of the spray solution

\begin{tabular}{|c|c|c|c|c|c|}
\hline $\begin{array}{c}\text { Error class, } \\
\%\end{array}$ & $\begin{array}{l}\text { Average } \\
\text { error, \% }\end{array}$ & Distance, $\mathrm{m}$ & $\begin{array}{l}\text { Cumulative } \\
\text { distance, } m\end{array}$ & Surface, $\mathbf{m}^{2}$ & $\begin{array}{l}\text { Cumulative } \\
\text { surface, } \mathbf{m}^{2}\end{array}$ \\
\hline $12.5 \ldots 15$ & 11.00 & 3.31 & 3.31 & 49.65 & 49.65 \\
\hline $10 \ldots 12.5$ & 14.57 & 3.26 & 6.57 & 48.90 & 98.55 \\
\hline $2.5 \ldots 5$ & 4.64 & 2.95 & 9.52 & 44.25 & 142.80 \\
\hline
\end{tabular}

The analysis of the obtained results shows that the area on which significant errors of application of the spray solution occurred (meaning more than $2.5 \%)$ is relatively small $\left(142.80 \mathrm{~m}^{2}\right)$. Also, in this case it can be observed that the maximum errors of application of the treatment do not exceed $15 \%$, and the cumulative area on which large errors occurred (between 10...15\%) is $98.55 \mathrm{~m}^{2}$.

Taking into account the flow values measured by the electromagnetic flow meter, the evolution of the regulated flow (compared to the reference value) in the case of opening during work of a section of the spraying boom (at a constant displacement velocity of $6 \mathrm{~km} \cdot \mathrm{h}^{-1}$ ) is represented in the graph (Fig. 4). 


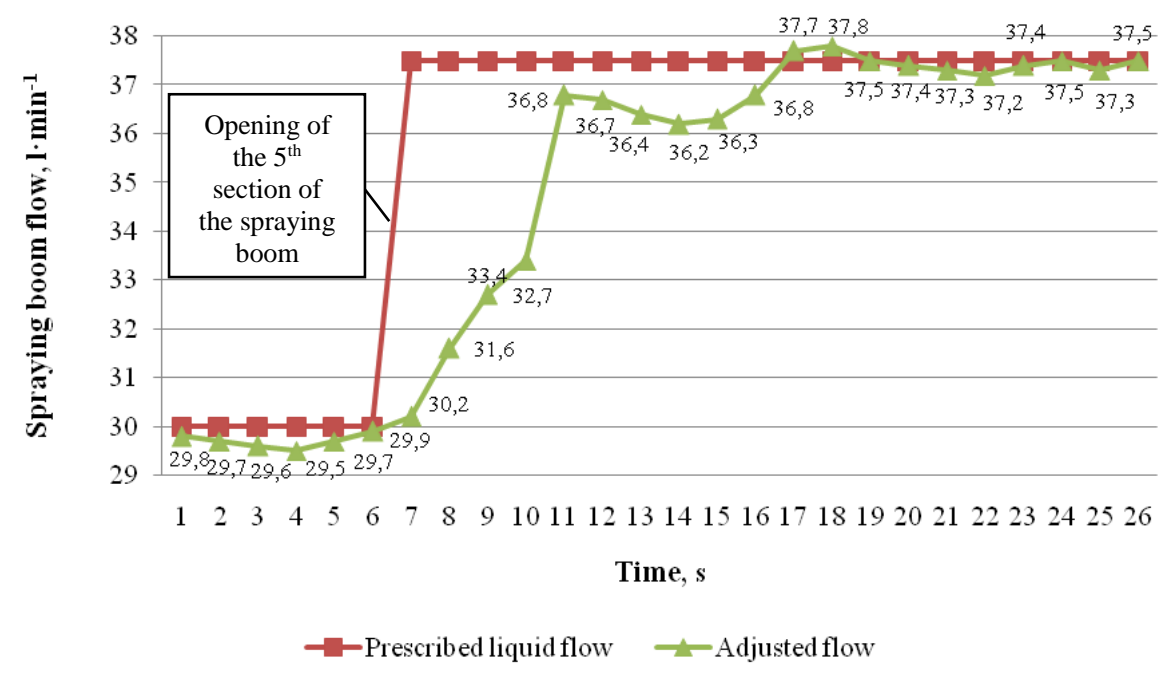

Fig. 4. Evolution of the regulated flow, compared to the reference value, in the case
of opening of an additional section of the spraying boom

For this working situation the values of distances and areas, corresponding to each category of treatment application errors, during the liquid flow adjustment process are presented in Table 3.

Table 3

\section{Influence of opening during work of an additional section of the spraying boom on the longitudinal distribution of the spray solution}

\begin{tabular}{|c|c|c|c|c|c|}
\hline $\begin{array}{c}\text { Error class, } \\
\%\end{array}$ & $\begin{array}{l}\text { Average } \\
\text { error, \% }\end{array}$ & Distance, $\mathbf{m}$ & $\begin{array}{l}\text { Cumulative } \\
\text { distance, } m\end{array}$ & Surface, $\mathbf{m}^{2}$ & $\begin{array}{l}\text { Cumulative } \\
\text { surface, } \mathbf{m}^{2}\end{array}$ \\
\hline$-17.5 \ldots-20$ & -17.57 & 3.32 & 3.32 & 49.80 & 49.80 \\
\hline$-10 \ldots-12.5$ & -11.86 & 3.32 & 6.64 & 49.80 & 99.60 \\
\hline$-2.5 \ldots-5$ & -3.33 & 3.32 & 9.96 & 49.80 & 149.40 \\
\hline
\end{tabular}

The results of the experiments show that the errors of application of the treatment were higher, reaching up to approx. $20 \%$, but the working flow is corrected very quickly (approx. 3.5 s), due to the decrease in the overall hydraulic resistance of the spraying boom. The decrease of the hydraulic resistance of the spraying boom automatically determines the increase of the liquid flow, thus facilitating the adjusting process. Also in this case, the area on which significant errors of application of the spray solution occurred (meaning more than $2.5 \%$ ) is relatively small $\left(149.40 \mathrm{~m}^{2}\right)$.

\section{Conclusions}

1. Experimental researches in laboratory conditions concerning the electronic process of flow regulation for sprinkling machines have shown a good sensitivity and a stable behaviour during operation of regulators of this type.

2. Taking into account the economic and environmental protection aspects, the data obtained demonstrate that the cumulative size of the surfaces on which significant errors of application of the spray solution occurred (meaning more than $2.5 \%$ ) is relatively small $\left(126.75-149.40 \mathrm{~m}^{2}\right.$ ).

3. The adjustment feature of the liquid flow highlights that the adjustment function is performed correctly and in an optimal time: approx. $5.5 \mathrm{~s}$ in case of a progressive and constant variation of the working speed and approx. $3.5 \mathrm{~s}$ in the case of opening of an additional section of the spraying boom.

4. Apparently, the obtained results indicate relatively high application errors, but it must be taken into account that the values used for plotting the flow characteristics are calculated based on measurements made using an electromagnetic flow meter (which has its own inertia); in reality the regulator ensures a faster adjustment. 


\section{References}

[1] Glodeanu M., Vasile C, Alexandru T. Experimental researches concerning the performances of electronic adjustment systems that equips sprinkling machines. Proceedings of International conference " $16^{\text {th }}$ International Multidisciplinary Scientific Geoconference SGEM 2016", June 30 July 6, 2016, Book 3, Vol. II, Albena, Bulgaria, pp. 119-126.

[2] Brîndușa P., Iliescu C., Faur D. Mesures electriques et transducteurs. Matrix Rom Publishing House, Romania, 2006, 247 p.

[3] Nagy M., Cota C., Roman M. etc. Method and technical means of measurements for evaluation of characteristics of field crop sprayers. International Conference "Environmentally Friendly Spray Applications techniques", Warsaw 4-8 October, 2004, pp. 139-140.

[4] Billingsley J. Robotics and automation for improving agriculture. Burleigh Dodds Series in Agricultural Science Publishing House, United States, 2019, 326 p.

[5] Oltean G. Electronic devices. U.T. Pres Publishing House, Cluj-Napoca, Romania, 2006, 317 p.

[6] Scherz P., Monk S. Practical Electronics for Inventors, Fourth Edition. McGraw-Hill Education Publishing House, OH, United States, 2016, 1056 p.

[7] Ivanov V. Sensors and transducers. Universitaria Publishing House, Craiova, Romania, 2018, 160 p.

[8] Ignea A., Stoiciu D. Electronic measurements, sensors and transducers. Politehnica Publishing House, Timisoara, Romania, 2007, 262 p.

[9] Pasca S., Tomescu N., Sztojanov I. Analog and digital electronics. Albastra Publishing House, ClujNapoca, Romania, 2008, vol. I, II, II, 995 p.

[10] Neitzel D. Electrical Safety Handbook McGraw-Hill Education Publishing House, OH, United States, 2016, $688 \mathrm{p}$.

[11] Edan Y., Kondo N., Shufeng H. Automation in agriculture. In: Nof, S.Y. (Ed.), Handbook of Automation, Berlin: Springer Verlag, 2009, 1128 p.

[12] Huyghebaert B., Mostade O., Braekman P. Overview of the sprayer inspection in Belgium. SPISE, Mitt. Biol. Bundesanst. Land-Forstwirtsch, 2004. 397 p.

[13] Nasr G.G., Yule A.J., Bending L. Industrial Spray and Atomisation, Design, Analysis and Applications. Springer-Verlag-London-Berlin, 2002, 497 p.

[14] Perger G., Petris R., Pesticide dose adjustment in vineyard spraying and potential for dose reduction, Agricultural Engineering International: The CIGR Ejournal X, 2008, pp. 248-253.

[15]Zhang Q., Pierce F.J. Agricultural Automation Fundamentals and Practices. CRC Press Publishing House, London, England, 2013, 411 p. 